\title{
Inhibition of Colletotrichum gloeosporioides and Control of Postharvest Anthracnose Disease on Mango Fruit Using Propionic Acid Combined with Bee-Carnauba Wax Emulsion
}

\author{
Do Chi Thinh ${ }^{1,2} \&$ Kaewalin Kunasakdakul ${ }^{3}$ \\ ${ }^{1}$ Post-Harvest Technology Research Institute, Chiang Mai University, Thailand \\ ${ }^{2}$ Department of Food Science, College of Food Industry, Da Nang, Vietnam \\ ${ }^{3}$ Department of Entomology and Plant Pathology, Faculty of Agriculture, Chiang Mai University, Thailand \\ Correspondence: Do Chi Thinh, Department of Food Science, College of Food Industry, 101B Le Huu Trac, Da \\ Nang, Vietnam. Tel: 84-905-099-078. E-mail: dochithinh@gmail.com
}

Received: September 22, 2013 Accepted: October 21, 2013 Online Published: November 15, 2013

doi:10.5539/jas.v5n12p110 URL: http://dx.doi.org/10.5539/jas.v5n12p110

\begin{abstract}
Anthracnose caused by Colletotrichum gloeosporioides is the most significant postharvest disease of mangos and negatively affect handling and marketing of mango fruits in Vietnam. A mixture of bee-carnauba wax and propionic acid has successfully inhibited linear growth and spore germination of $C$. gloeosporioides (in vitro) and prevented anthracnose diseases of mango fruits (in vivo). A complete reduction in mycelial growth and spore germination was observed when a mixture of $0.09 \%$ propionic acid and $8 \%$ bee-carnauba wax was used. Similar results were shown on mango fruits treated with $0.12 \%$ propionic acid which obtained a highly protective effect against anthracnose disease. The results of this study revealed that propionic acid could be used as a safe fungicide alternative against anthracnose disease, which causes economic losses during transportation, marketing and storage.
\end{abstract}

Keywords: anthracnose, disease, inhibition, propionic acid, wax

\section{Introduction}

Mangos (Mangifera indica L.) are a major tropical fruit in both domestic and export markets of Vietnam. Among Vietnamese mango cultivars, Cat Hoa Loc mango is the most popular cultivar because of its good appearance, delicious taste and flavour. Its production ranks the first among commercial mango cultivars in Vietnam. The Vietnamese government supports the expansion of the production area for Cat Hoa Loc mango. Anthracnose, caused by Colletotrichum gloeosporioides, is a significant postharvest disease of Vietnamese mango fruit cv. Cat Hoa Loc during transportation, storage and marketing (Binh et al., 2001; Linh, 2007; Duc et al., 2008). A recent report showed 34\% of mango fruit in domestic markets Vietnam were infected with anthracnose (Duc et al., 2008).

Anthracnose usually occurs only in ripe fruits, as the fungus remains dormant in immature fruit during the growing season, and it is incited in the postharvest period (Nishijima, 1993; Ploetz, 2009). Fungicides are commonly used as the primary tool to control pre- and postharvest anthracnose diseases. However, their use is restricted due to public concerns over possible toxicological risks to people (Ansari, 1995). In addition, there has been increasing public pressure to reduce the use of synthetic fungicides in agricultural products and the environment (Prusky et al., 2009). Therefore, alternatives to control anthracnose in order to guarantee safe agricultural production as well as reduce environmental pollution are of interest.

Some research results have indicated that propionic acid can inhibit the growth of fungi, yeast (Haque et al., 2009; Selwet, 2009), and bacteria (Wang et al., 2009). Higgins and Blunkhaus (1999) found that a concentration of $0.20 \%$ or less of propionic acid was able to reduce the growth rate of Aspergillus spp., Geotrichum spp., Mucor spp., Fusarium spp., Penicillium spp., and Scopulariopsis spp. to 50\%. Propionic acid at a concentration of $0.15 \%$ reduced the growth of Penecillium expansum by more than 70\% (Larous et al., 2007).

Research work in propionic acid as a safe antifungal to control anthracnose disease of mango has yet to develop an effective alternative. Hence, the objectives of this study were to investigate the effects of propionic acid on control of anthracnose disease caused by $C$. gloeosporioides in mango fruits, evaluating the antifungal activity of 
propionic acid against pathogen in vitro, and its effect on disease incidence on mango fruits. The effect of bee-carnauba wax on inhibition $C$. gloeosporioides and controlling postharvest anthracnose disease on mango fruit were also studied.

\section{Materials and Methods}

\subsection{Fruits}

Mango (Mangifera indica L.) fruits Cat Hoa Loc cv. were harvested at 75-84 days after fruit set and sorted based on colour, shape, specific gravity (1.00-1.02), and weight (Thinh et al., 2013a). Fruits needed to be free of physical injuries or disease infection. Before treatments, fruit were surface disinfected with $2 \%$ sodium hypochlorite for 3 min, then they was rinsed with tap water and air-dried.

\subsection{Pathogen Culture}

The small pieces of anthracnose symptomatic tissue obtained from infected mango fruit peels approximately $3 \times 3$ $\mathrm{mm}$ were surface sterilized and placed on Petri plates with Potato Dextrose Agar (PDA). The pathogen was isolated after an incubation period of 7-11 days at ambient temperature $\left(29-33^{\circ} \mathrm{C}\right)$ in alternative 12 hours of darkness and light exposure. The observation and identification of conidia morphology were carried out under light microscopy according to Binh et al. (2001) and Jayasinghe \& Fernando (2009). Subculture and reisolations of the fungus were done in the same culture medium.

\subsection{Preparation of Bee-Carnauba Wax Emulsion}

Wax emulsion was prepared following Thinh et al. (2013b). The bees wax and carnauba wax in the ratio of 3 to 2 were melt at $80-85^{\circ} \mathrm{C}$ for $25-30$ minutes by a magnetic stirrer. $1.5 \%$ oleic acid, $0.08 \%$ palmitic acid, and $5 \%$ ammonia were added to the mixture before the mixture was blended. Water was added to the mixture during stirring and blending for adjustment concentration of wax emulsion to 5, 6 and 7\%.

\subsection{Assessment of Mycelial Growth}

The effects of bee-carnauba wax emulsion (BC) and/or propionic acid on the growth of C. gloeosporioides were studied on PDA plates. An agar disk (5 mm diameter) from the same physiological age of $C$. gloeosporioides (6 days old) was placed in the center of a PDA plate containing 0.03, 0.06, 0.09 and $0.12 \%$ propionic acid or each concentration of propionic acid combined with $4.0,6.0$ and $8.0 \% \mathrm{BC}$, then incubated at $25^{\circ} \mathrm{C}$. Propionic acid and $\mathrm{BC}$ were added to the PDA after media autoclaving but before solidification. Control plates contained PDA media only. Daily radial growth measurements were taken with a caliper until mycelia reaching the maximum (after 7 days of incubation). Five replications were carried out for each treatment. The effect of treatment on mycelial growth of $C$. gloeosporioides was performed in percent inhibition by using the following formula (Skidmore and Dickinson, 1976):

$$
\text { Growth inhibition }=\left(C-\mathrm{T}_{\mathrm{i}}\right) / \mathrm{C} \times 100
$$

where $\mathrm{C}=$ the radial mycelial growth in control and $\mathrm{T}_{\mathrm{i}}=$ the radial mycelial growth in the treatments.

\subsection{Assessment of Spore Germination on Glass Slides}

Six day-old conidial C. gloeosporioides cultures were harvested by scraping them off the media and suspending them in sterile distilled water. The mycelium and the spore mixture was filtered through a 2-layer cheesecloth. Spore suspension was mixed with different propionic acid concentrations $(0.03,0.06,0.09$, and $0.12 \%)$ and $\mathrm{BC}$ $(4,6$ and $8 \%)$, then the spore suspension was adjusted to approximately $1.5 \times 10^{2} \mathrm{CFU} \mathrm{mL}^{-1}$ by hemacytometer (treated spore suspension). Ten $\mu \mathrm{L}$ of PDA aqueous medium was dropped gently on the sterile microscope slides to obtain a thin agar layer, and then a drop of treated spore suspensions was spread on each slide. The slides were held in a moisture chamber for $24 \mathrm{hrs}$ of incubation at $24^{\circ} \mathrm{C}$. A slide containing $5 \mu \mathrm{L}$ of sterile water with spore suspensions was used as control. To stop spores germinating, a drop of lacto phenol cotton blue was placed on the slide. The slides were examined under microscope $(\times 40)$ for recording the percentage of spore germination (Banos et al., 2003; Linh, 2007). Five replications were carried out for each treated spore suspension. The percentage reduction of sporulation ( $\mathrm{Sp}$ ) was calculated using the formula:

$$
\mathrm{Sp}=\left(\mathrm{M}_{1}-\mathrm{M}_{2}\right) / \mathrm{M}_{1} \times 100
$$

where $\mathrm{Sp}=$ percentage reduction in sporulation; $\mathrm{M}_{1}=$ sporulation on the control; $\mathrm{M}_{2}=$ sporulation on the treated spore suspensions.

\subsection{Assessment of Anthracnose Diseases of Mango Fruits}

The control of propionic acid and BC (4.0, 0.6 and $8.0 \%)$ to anthracnose diseases of mango fruits was evaluated by the wounding technique following Dinh et al. (2003) and (Linh, 2007) with modification. The mango fruits 
prepared in 2.1 were wounded gently with a sterilized needle knife at the equator $(3 \mathrm{~mm}$ deep, $1 \mathrm{~mm}$ wide and 5 mm length). Each fruit was inoculated with treated spore suspension (from 2.4) on one side; the other side was non-inoculated as control. Next, the infected fruits were coated by dipping them in BC 4.0, 0.6 and $8.0 \%$ or BC combined with $0.08,0.12$ and $0.16 \%$ propionic acid for 5 seconds (post-infection) and left at ambient temperature $\left(29-33^{\circ} \mathrm{C}\right)$ until the surfaces were almost dry (approximately $3-4 \mathrm{~min}$ ). Then they were stored at $23-25^{\circ} \mathrm{C}$ for ripening (the best temperature for ripening Cat Hoa Loc mango fruit (Thinh et al., 2013a). In this study, each treatment consisted of two 25-fruit replicates. Control pathogen evaluation of propionic acid and bee-carnauba wax were based on the severity index and anthracnose incidence. The severity index was based on the percent of infected skin area and ranked from 0 to 4 , where: $0=0 \%$ of fruit surface rotten, $1=1-5 \%$, (initially damaged), $2=$ $6-15 \%$ (lightly damaged), $3=16-30 \%$ (moderately damaged), $4=>31 \%$ (severely damaged). The means of the different severity indexes were compared by Tukey's multiple range tests at $5 \%$ significance. The anthracnose incidence was the percent of disease fruit of each treatment.

Treatments were arranged in a completely randomized design.

\section{Results and Discussion}

3.1 Effect of Propionic Acid Alone and Combined with Bee-Carnauba Wax on Mycelial Growth of C. gloeosporioides
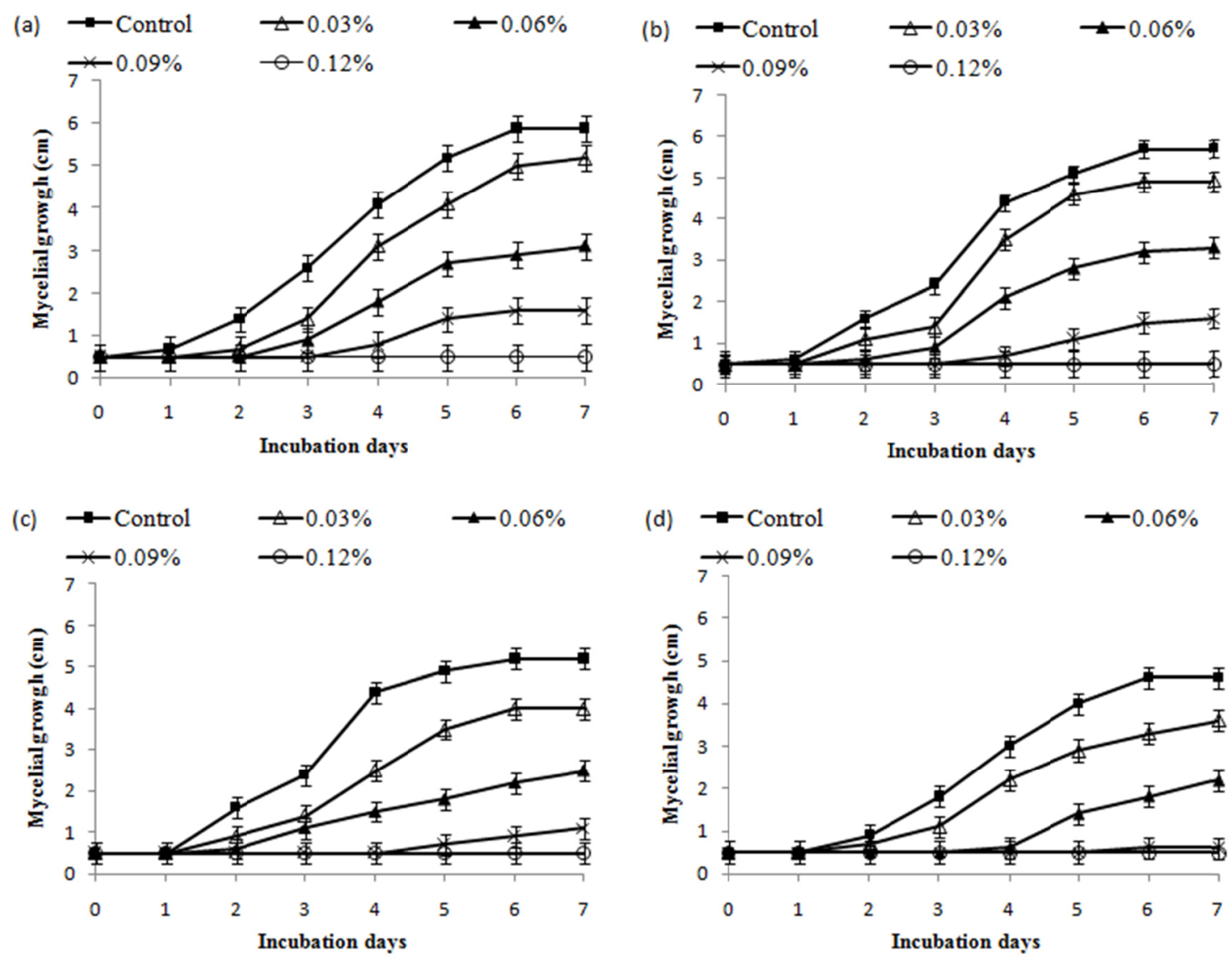

Figure 1. Effect of propionic acid at various concentrations with: a) $0 \%$ bee-carnauba wax; b) $4 \%$ bee-carnauba wax; c) $6 \%$ bee-carnauba wax and d) $8 \%$ bee-carnauba wax on mycelial growth of C. gloeosporioides during a 7-day incubation period

Effect of propionic acid on mycelial growth of $C$. gloeosporioides is shown in Figure 1. All propionic acid concentrations reduced mycelial growth of tested $C$. gloeosporioides. Without BC, complete inhibition was obtained by propionic acid concentrations of $0.12 \%$ during the 7 -day incubation period while propionic acid concentrations of $0.03,0.06$ and $0.09 \%$ could reduce mycelial growth of $C$. gloeosporioides $11.86,47.46$ and 
$72.88 \%$, respectively. Mycelial growth began on the third day and the fourth day of the incubation period at $0.06 \%$ and $0.09 \%$ propionic acid while this was the second day at $0.03 \%$ (Figure 1a). Regardless of the concentration of BC, mycelial growth of $C$. gloeosporioides was inhibited completely at $0.12 \%$ propionic acid (Figure 1a-d). The restraint development hyphae was intensified when propionic acid was combined with bee-carnauba wax. Mixture of $4 \%$ bee-carnauba wax and $0.09 \%$ propionic reduced mycelial growth $71.93 \%$ while that the result was $73.62 \%$ if bee-carnauba wax was $6 \%$ instead of $4 \%$.

Antifungal activities of propionic acid were reported in previously research. Larous et al. (2007) found that propionic acid at a concentration of $0.2 \%$ could inhibit the growth of Penecillium expansum completely. Inhibition of the growth of propionic acid is most effective in molds $>$ yeast $>$ bacteria (Kung et al., 2000). At concentration $0.1 \%$, propionic acid completely inhibited the yield of mycelia and sclerotia of Aspergillus parasiticus (Chourasia, 1993).

For the combination of propionic acid and mixing waxes, mycelial growth of $C$. gloeosporioides was reduced as mixing wax concentrations increasing. This may be the result of antimicrobial actions of bees wax and carnauba wax. The result show that at $0.03 \%$ propionic acid, 6 and $8 \%$ bee-carnauba wax could reduce mycelial growth of C. gloeosporioides at 11.86 and $22.86 \%$ respectively (Figure 1c-d). Bees wax was found to be particularly active against Bacillus alvei, Proteus vulgaris, Salmonella gallinarum and Bacillus subtilis (Kacániová et al., 2012). Gonçalves et al. (2010) reported that mycelial growth of Rhizopus stolonifer was completely inhibited at $1 \%$ carnauba wax. Additionally, they found there was no mycelial growth of Monilinia fructicola in any of carnauba wax concentrations.

\subsection{Effect of Propionic Acid Alone or Combined with Bee-Carnauba Wax on Spore Germination of C. gloeosporioides}

The results from Table 1 show that propionic acid was affected on spore germination of C. gloeosporioides. The spore germination of $C$. gloeosporioides was decreased when propionic acid concentration increased. The inhibition of spore germination was 36.60 and $84.72 \%$ at 0.06 and $0.09 \%$ of propionic acid respectively. Propionic acid at $0.12 \%$ could inhibit spore germination of $C$. gloeosporioides completely. For the combination of propionic acid with bee-carnauba wax, the inhibition of spore germination of $C$. gloeosporioides increased as the wax concentration increased. The inhibition of spore germination was $8.30,14.34$ and $24.34 \%$ for the media containing $0.03 \%$ of propionic acid plus bee-carnauba wax at 4,6 and $8 \%$, respectively. There was very little information about the effect of carnauba wax on spore germination of $C$. gloeosporioides, but this was reported about other fungus species. El-Mougy et al. (2012) reported that carnauba wax had no inhibitory effect against Geotricum candidum (sour rot), Penicilium digitatum (green mould) or Penicilium italicum (blue mould). Nevertheless, Gonçalves et al. (2010) found that nectarines covered with $9 \%$ carnauba wax could inhibit $50 \%$ of spore germination for Monilinia fructicola and $90 \%$ for Rhizopus stolonifer.

Table 1. The percent inhibition (\%) of spore germination of C. gloeosporioides at various concentrations of propionic acid and bee-carnauba waxa

\begin{tabular}{ccccc}
\hline \multirow{2}{*}{ Concentration of propionic acid (\%) } & \multicolumn{5}{c}{ Concentration of Bee-Carnauba wax (\%) } \\
\cline { 2 - 5 } & $\mathbf{0}$ & $\mathbf{4}$ & $\mathbf{6}$ & $\mathbf{8}$ \\
\hline 0.03 & $5.66 \pm 0.23 \mathrm{a}$ & $8.3 \pm 0.3 \mathrm{a}$ & $14.34 \pm 0.84 \mathrm{ab}$ & $24.34 \pm 0.33 \mathrm{~b}$ \\
0.06 & $36.6 \pm 1.31 \mathrm{c}$ & $50 \pm 1.79 \mathrm{~d}$ & $62.26 \pm 0.6 \mathrm{e}$ & $66.98 \pm 1.23 \mathrm{e}$ \\
0.09 & $84.72 \pm 1.41 \mathrm{f}$ & $85.09 \pm 1.1 \mathrm{f}$ & $92.26 \pm 0.91 \mathrm{fg}$ & $99.06 \pm 0.3 \mathrm{~g}$ \\
0.12 & $99.25 \pm 0.35 \mathrm{~g}$ & $99.43 \pm 0.38 \mathrm{~g}$ & $99.43 \pm 0.38 \mathrm{~g}$ & $100 \pm 0 \mathrm{~g}$ \\
\hline
\end{tabular}

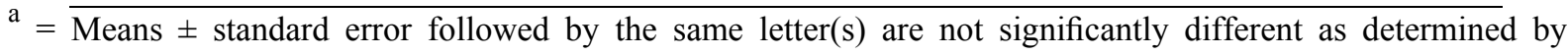
Tukey's multiple-range test $\mathrm{P}<0.05$.

\subsection{Effect of Propionic Acid Alone or Combined with Bee-Carnauba Wax on Anthracnose Diseases of Mango Fruits}

Table 2 shows the results of disease incidence and severity for each treatment on artificially inoculated mango fruits at ripening stage. The reduction of anthracnose disease of propionic acid was increasing as concentration acid increased. There was $10 \%$ anthracnose incidence in fruit treated with $0.12 \%$ propionic acid combined with $8 \%$ bee-carnauba wax, while these were about 50 and $80 \%$ in fruit treated with 0.09 and $0.06 \%$ propionic acid 
respectively. Combination of propionic acid and bee-carnauba wax improved the inhibition of C. gloeosporioides. The effected skin area was $19.67,11.83$ and $2.83 \%$ in mango fruit treated with $0.09 \%$ propionic acid plus wax at 4 , 6 and $8 \%$, respectively.

There is no information available about the effect of propionic acid on C. gloeosporioides. Cherrington et al. (1991) mentioned different pathways of organic acids related to $\mathrm{pH}$ with respect to their anti-bacterial. The antibacterial activity increased as the $\mathrm{pH}$-value decreased, which involved membrane transport. On the contrary, Razavi-rohani and Griffiths (2007) found that the antifungal activity of propionic acid did not change when the $\mathrm{pH}$ increased or decreased. The effect of propionic acid should be demonstrated via another pathway.

Some authors demonstrated the effect of propionic acid on preventing fungi disease. Waks et al. (1985) found that lower incidence of mold rots in citrus fruit could been attributed to the action barrier of wax. A wax barrier could prevent contact between the spores and wounds on the fruit peel and might prevent spore germination and fruit infection. Moreover, data from Cruz et al. (2002) showed that carnauba wax contains defense proteins like chitinase and glucanases, which appear to inhibit the early growth of $C$. lindemuthianum, $C$. musae and $F$. oxysporum and cause morphological alterations during these pathogens' growth.

Table 2. Effect of various concentrations of propionic acid and bee-carnauba wax on anthracnose disease ${ }^{\mathrm{b}}$

\begin{tabular}{cccc}
\hline \multirow{2}{*}{ Treatments } & \multicolumn{2}{c}{ Severity index } & Anthracnose incidence (\%) \\
\cline { 2 - 4 } & \% skin area & Scores & 100.00 \\
\hline $4 \%$ wax $+0.06 \%$ acid (1) & $40 \pm 1.36 \mathrm{f}$ & 4 & 100.00 \\
$4 \%$ wax $+0.09 \%$ acid (2) & $19.67 \pm 1.48 \mathrm{~d}$ & 3 & 80.00 \\
$4 \%$ wax $+0.12 \%$ acid (3) & $7.67 \pm 0.46 \mathrm{bc}$ & 2 & 100.00 \\
$6 \%$ wax $+0.06 \%$ acid (4) & $32.67 \pm 0.82 \mathrm{e}$ & 4 & 70.00 \\
$6 \%$ wax $+0.09 \%$ acid (5) & $11.83 \pm 0.7 \mathrm{c}$ & 2 & 60.00 \\
$6 \%$ wax $+0.12 \%$ acid (6) & $3.17 \pm 0.45 \mathrm{ab}$ & 1 & 80.00 \\
$8 \%$ wax $+0.06 \%$ acid (7) & $22.03 \pm 1.24 \mathrm{~d}$ & 3 & 50.00 \\
$8 \%$ wax $+0.09 \%$ acid (8) & $2.83 \pm 0.52 \mathrm{ab}$ & 1 & 10.00 \\
$8 \%$ wax $+0.12 \%$ acid (9) & $0.67 \pm 0.32 \mathrm{a}$ & 1 & 100.00 \\
\hline Control & $66.33 \pm 1.31 \mathrm{~g}$ & 4 & \\
\hline
\end{tabular}

$\mathrm{b}=$ Means \pm standard error followed by the same letter(s) are not significantly different as determined by Tukey's multiple-range test $\mathrm{P}<0.05$.

The application of wax on post-infection or pre-infection had significant effect on the severity and incidence of disease in mangos. Our preliminary study application of mixture $0.09 \%$ propionic acid and $6 \%$ bee-carnauba wax on pre-inoculated reduced severity $17.54 \%$ and incidence $90 \%$ (data not show here), while in this study these numbers were 11.83 and 80\%, respectively. Bompeix and Morgat (1977) demonstrated that carnauba wax reduced postharvest decay by $70 \%$ on apples when applied as a post-infection treatment associated with low temperatures. In the post-infection, the spore fungus established on treated fruit similar to the real infected fruit.

In this research, the concentration of propionic acid was not higher than $0.12 \%$ because the bee-carnauba wax emulsion was unstable at higher concentrations. Furthermore, a high concentration propionic acid is corrosive and volatile (Dibner \& Buttin, 2002).already in the fruit

\section{Conclusions}

The results show that $0.12 \%$ propionic acid is able to inhibit the mycelium growth and spore germination of $C$. gloeosporioides as well as to reduce postharvest diseases of mango. This result suggests that propionic acid could be used to control anthracnose disease of other fruits. The new formula containing a mixture of $6 \%$ bee-carnauba wax and $0.12 \%$ propionic acid could be appropriate for commercial use in packinghouses since these formulas are considered safe for wide consumption. Further research identifying suitable added components for stabilizing the bee-carnauba wax will help increase the concentration of propionic acid in the wax emulsion to intensify the antifungal activity of the formula. 


\section{Acknowledgements}

The authors acknowledge funding from the Vietnam Government; research equipments from the College of Food Industry, Vietnam; and the Postharvest Technology Research Institute, and Faculty of Agriculture, Chiang Mai University, Thailand.

\section{References}

Ansari, M. M. (1995). Control of Sheath blight of rice by plant extracts. Indian Phytopathology, 48(3), $268-270$.

Banos, S. B., Lopez, M. H., Molina, E. B., \& Wilson, C. L. (2003). Effects of chitosan and plant extracts on growth of Colletotrichum gloeosporioides, anthracnose levels and quality of papaya fruit. Crop Protection, 22, 1087-1092. http://dx.doi.org/10.1016/S0261-2194(03)00117-0

Binh, L. N., Do, L., Thanh, H. V., \& Hoa, L. V. (2001). Biological characteristics of Colletotrichum gloeosporioides penz. infecting under Lab. Condition (pp. 361-368). SOFRI, Vietnam (in Vietnamese).

Bompeix, G., \& Morgat, F. (1977). Coating waxes, antiscald components, fungicides and storage of apples. Fruits, 32, 189-195.

Cherrington, C. A., Hinton, M., Mead, G. C., \& Chopra, I. (1991). Organic acids: chemistry, antibacterial activity and practical applications. Advances in Microbial Physiology, 32, 87-107.

Chourasia, H. K. (1993). Growth, sclerotia and aflatoxin production by Aspergillus parasiticus: influence of food preservatives. Letters in Applied Microbiology, 17, 204-207.

Cruz, M. A. L., Gomes, V. M., Fernandes, K. V. S., Machado, O. L. T., \& Xavier-Filho, J. (2002). Identification and partial characterization of a chitinase and a $\beta$-1,3-glucanase from Copernicia cerifera wax. Plant Physiology and Biochemistry, 40, 11-16.

Dibner, J. J., \& Buttin, P. (2002). Use of organic acids as a model to study the impact of gut microflora on nutrition and metabolism. Poultry Science, 11, 453-463.

Dinh, S. Q., Chongwungse, J., Pongam, P., \& Sangchote, S. (2003). Fruit infection by Colletotrichum gloeosporioides and anthracnose resistance of some mango cultivars in Thailand. Australasian Plant Pathology, 32, 533-538.

Duc, N. D., Nissen, R. J., Chau, N. M., Khanh, V. C., Binh, N. V., Anh, S. T., .. Oanh, T. T. K. (2008). Improving domestic market and export fruit in Vietnam through improved supply chain and postharvest technology (pp. 47-58). MARD, Vietnam (in Vietnamese).

El-Mougy, N. S., Abdel-Kader, M. M., \& Aly, M. H. (2012). Effect of a new chemical formula on postharvest decay incidence in citrus fruit. Journal of Plant Protection Research, 52, 156-164.

Gonçalves, F. P., Martins, M. C., Junior, G. J. S., Lourenço, S. A., \& Amorim, L. (2010). Postharvest control of brown rot and Rhizopus rot in plums and nectarines using carnauba wax. Postharvest Biology and Technology, 58(3), 211-217. http://dx.doi.org/10.1016/j.postharvbio.2010.08.004

Haque, M. N., Chowdhury, R., Islam, K. M. S., \& Akbar, M. A. (2009). Propionic acid is an alternative to antibiotics in poultry diet. Bangladesh Journal of Animal Science, 38, 115-122.

Higgins, C., \& Blunkhaus, F. (1999). Efficacy of several organic acids against molds. The Journal of Applied Poultry Research, 8, 480-487.

Jayasinghe, C. K., \& Fernando, T. H. P. S. (2009). First report of Colletotrichum acutatum on mangifera indica in Sri lanka. Ceylon Journal of Science (Biological Sciences), 38, 31-34.

Kacániová, M., Vuković, N., Chlebo, R., Haščík, P., Rovná, K., Cubon, J., .. Pasternakiewcz, A. (2012). The antimicrobial activity of honey, bee pollen loads and beeswax from Slovakia. Archives of Biological Science Belgrade, 64, 927-934. http://dx.doi.org/10.2298/ABS1203927K

Kung, Jr., Robinson, J. R., Ranjit, N. K., Chen, J. H., \& Golt, C. M. (2000). Microbial populations, fermentation end products, and aerobic stability of corn silage treated with ammonia or a propionic acid-based preservative. Journal of Dairy Science, 83, 1479-1486.

Larous, L., Hendel, N., Abood, J. K., \& Ghoul, M. (2007). The growth and production of Patulin mycotoxin by Penecillium expansum on apple fruits and its control by the use of propionic acid and sodium benzoate. Arab Journal of Plant Protection, 25, 123-128. 
Linh, T. T. T. (2007). Effect of ozone liquid and anolyte solution on anthracnose on Cat Chu mango and Cat Hoa Loc mango in storage. M.S. Thesis. Can Tho University, Vietnam (in Vietnamese).

Nishijima, W. (1993). Mango diseases and their control. Retrieved from http://www.ctahr.hawaii.edu/ oc/freepubs/pdf/HITAHR_04-06-93_20-24.pdf

Ploetz, R. (2009). Anthracnose of mango-Management of the most important pre and post harvest disease. Retrieved from http:/www.mango.org/media/55703/anthracnose_of_mango.pdf

Prusky, D., Kobiler, I., Miyara, I., \& Alkan, N. (2009). Fruit diseases. In R. E. Litz (Ed.), CABI: The Mango: Botany, Production and Uses (pp. 210-239).

Razavi-rohani, S. M., \& Griffiths, M. W. (2007). Antifungal effects of sorbic acid and propionic acid at different $\mathrm{pH}$ and $\mathrm{NaCl}$ conditions. Journal of Food Safety, 19(2), 109-120.

Selwet, M. (2009). Effect of propionic and formic acid mixtures on the fermentation, fungi development and aerobic stability of maize silage. Polish Journal of Agronomy, 1, 37-42.

Skidmore, A. M., \& Dickinson, C. H. (1976). Colony interactions and hyphal interference between Septoria nodorum and phylloplane fungi. Transactions of the British Mycological Society, 66, 57-64.

Thinh, D. C., Uthaibutra, J., \& Joomwong, A. (2013a). Effect of storage temperatures on ripening behavior and quality change of Vietnamese mango cv. Cat Hoa Loc. International Journal of Bio-Technology and Research, 3, 19-30.

Thinh, D. C., Uthaibutra, J., \& Joomwong, A. (2013b). The suitable coating wax for Vietnamese mango fruit cv. Cat Hoa Loc. 13th asean Food Conference, Singapore. Retrieved from http://www.cvent.com/events/asean-food-conference/custom-116-c8a457d5a2614beaa8dd48024b8c3b5c.as $\mathrm{px}$

Waks, J., Schiffmann-Nates, M., Lomaniec, E., \& Chalutz, E. (1985). Relation between fruit waxing and development of rots in citrus fruit during storage. Plant Disease, 69, 869-870.

Wang, Y., Zhang, Y., Wang, J., \& Meng, L. (2009). Effects of volatile fatty acid concentrations on methane yield and methanogenic bacteria. Biomass and Bioenergy, 33, 848-853. http://dx.doi.org/10.1016/j.biombioe.2009.01.007

\section{Copyrights}

Copyright for this article is retained by the author(s), with first publication rights granted to the journal.

This is an open-access article distributed under the terms and conditions of the Creative Commons Attribution license (http://creativecommons.org/licenses/by/3.0/). 